\title{
A Compact Double-T Monopole Antenna for Dual Wideband Wireless Communications Systems
}

\author{
${ }^{1}$ Ram Kishore Sutrakar, ${ }^{2}$ Sunil Kumar Tripathi, ${ }^{3}$ Ankita Sharma \\ ${ }^{1}$ TIT (Excellence), Bhopal ${ }^{2}$ RKDF college of Engg, Bhopal. ${ }^{3}$ PIES, Bhopal
}

\begin{abstract}
This work carries a dual band monopole antenna design specially meant for wireless applications. The proposed antenna consists of a rectangular patch monopole in which a slot is cut in order to obtain a dual band operation and size reduction. The antenna operates in frequency band 2.3 to $3.4 \mathrm{GHz}$ and 4.95 to 5.85 GHz. These bands are now widely used in wireless communications. This miniaturized dual band monopole antenna proves to be an effective option for wireless devices to communicate with the outside world. We present a novel compact printed dual wideband double-T antenna, which consists of two stacked T-shaped monopoles.
\end{abstract}

Keywords: -Dual Band, Directivity, Monopole Antenna, Size Reduction.

\section{Introduction}

Advancement of antenna design is a fundamental part of any wireless system due to growth of wireless communication \& information transfer using handsets \& personal communication system devices. It is necessary at the same time that the system must radiate low power and provide reliable communication in terms of voice as well as data. Service providers \& users demand wireless units with antennas which are compact and small. Additionally it should be cost effective for manufacturability and easy to integrate with wireless communication system. The electrical characteristics that should be considered while designing the antenna include operating frequency, VSWR, return loss (input impedance, bandwidth, gain directivity \& radiation pattern.

These design criteria has led antenna designers to consider a wide variety of antenna structures to meet the often conflicting needs for wireless systems. Due to increased usage in residential and office areas, these systems are required to be low profile, low cost as well as highly effective and efficient. The increasing popularity of indoor wireless network capable of high-speed transfer rate is prompting for the development of efficient broadband antennas. A key requirement of a WLAN and WiMax systems are that it should be low profile, where it is almost invisible to the user. For this reason the monopole antennas are the only choice available for use due to their small area and the ability to be designed to blend with surroundings. Another important thing to look to is the cost and in this sense also monopole antenna is the only option. Monopole is a type of the radio antenna formed by replacing one half of a dipole antenna with a ground plane at right angles to the remaining half.

Printed monopoles have been recently proposed as suitable contenders with many variations suggested for dualband operation [1]. In order to satisfy the IEEE 802.11 WLAN standards in the $2.4 \mathrm{GHz}$ (2400-2484 $\mathrm{MHz})$ and $5.2 \mathrm{GHz}(5150-5350 \mathrm{MHz})$ bands, dual-band operations of the printed monopole antennas are required [2]. Also the dual-band printed dipole antennas are investigated [3].This paper contains such a monopole antenna design that effectively covers bands 2.3 to $3.4 \mathrm{GHz}$ and 4.95 to $5.85 \mathrm{GHz}$ that is used now-adays for wireless applications. We present a novel compact printed dual wideband double-T antenna, which consists of two stacked T-shaped monopoles.

\section{Related Work}

Many antennas are available for wireless applications. Dual band monopole antennas have been reported [4]-[8] but these however offer a narrow impedance bandwidth characteristic. Wideband Printed Monopole Antenna [9] was introduced by Chien-Yuan Pan, Tzyy-Sheng Horng, Wen-Shan Chen, and Chien-Hsiang Huang for WLAN/WiMAX Applications in 2007. The proposed monopole wideband antenna operating in dual band satisfied not only the wireless local area network (WLAN) applications; also accomplish the worldwide interoperability for microwave access applications (WiMax).

\section{Design Procedure}

The proposed antenna is formed on two stacked T-shaped monopoles, which are operating both at quarter wavelength, and are printed in the front of FR4 substrate of thickness $0.8 \mathrm{~mm}$ and relative permittivity 4.4. The substrate has a length $\mathrm{L}_{\mathrm{s}}=25 \mathrm{~mm}$ and the width $\mathrm{W}_{\mathrm{s}}=20 \mathrm{~mm}$. The dimensions of the partial conducting ground plane are $20 \times 10 \mathrm{~mm}^{2}$. The excitation is launched through a $50 \Omega$ microstrip feedline, which has the 
length $\left(\mathrm{L}+\mathrm{h}_{2}\right)=14 \mathrm{~mm}$ and the width $\mathrm{w}_{\mathrm{f}}=1.5 \mathrm{~mm}$, where $h_{2}$ denotes the distance between the feed point of first $\mathrm{T}$-arm radiator and the ground plane. The second Term radiator element is placed at $h_{l}=10.5 \mathrm{~mm}$ away partial ground plane. The two arms are connected by vertical strip with width of $\mathrm{w}=1.5 \mathrm{~mm}$. The two portions of the first T-arm are not equal $\left(\mathrm{L}_{21}=5.5 \mathrm{~mm}\right.$ and $\left.\mathrm{L}_{22}=6 \mathrm{~mm}\right)$, but the second $\mathrm{T}$-arm is symmetrical $\left(\mathrm{L}_{1}=7.75 \mathrm{~mm}\right)$. The width of the two T-arms are the same $\mathrm{W}_{1}=\mathrm{W}_{2}=3.5 \mathrm{~mm}$.

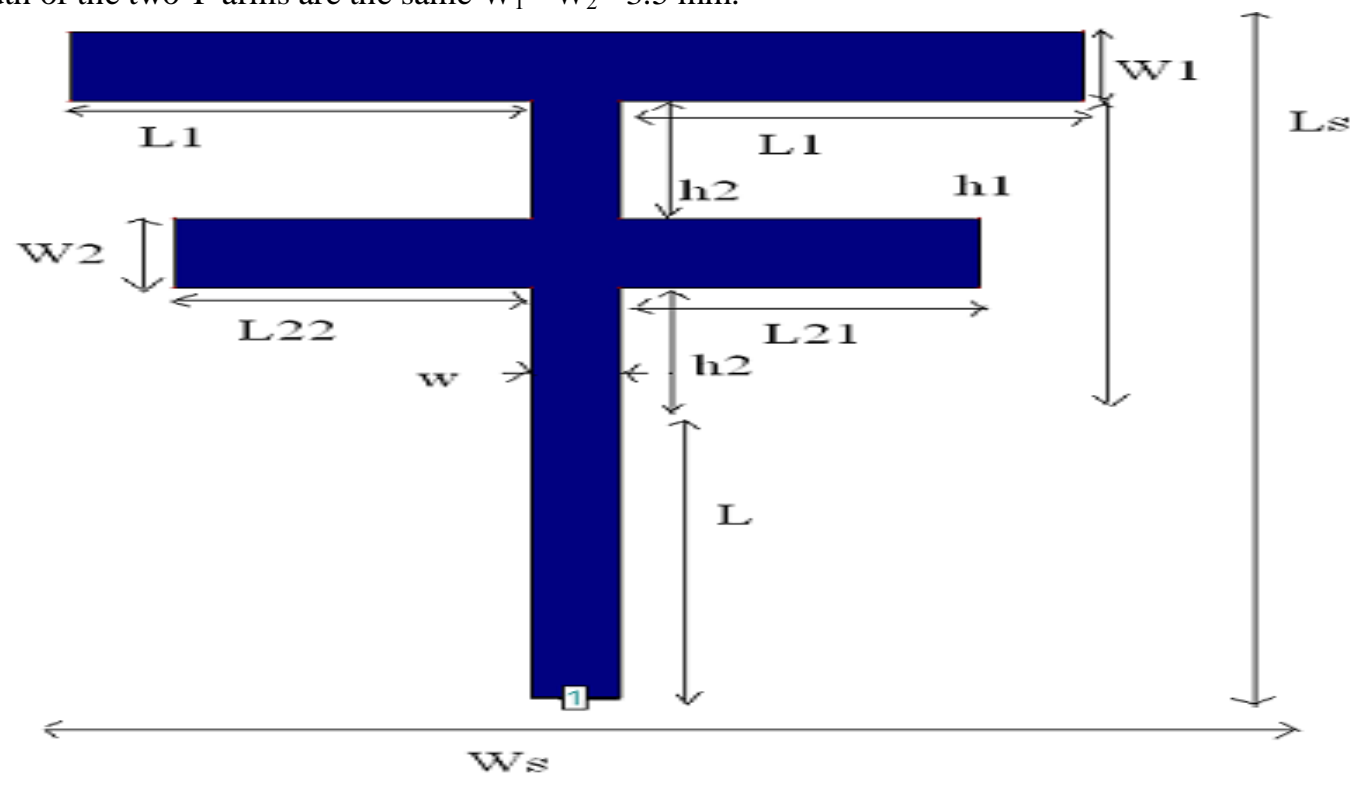

Fig.1. geometry of the proposed antenna

IV. Simulation Results of The Miniaturized Monopole Antenna

The proposed antenna operates at the dual wideband from 2300 to $3400 \mathrm{MHz}$ and 4950 to $5850 \mathrm{MHz}$ shown in fig.2, which satisfies the IEEE 802.11 WLAN standards in the $2.4 \mathrm{GHz}(2400-2484 \mathrm{MHz})$, IEEE 802.11a (5150-5350 MHz, 5725-5825 MHz) and HiperLAN/2 (5470-5725) bands (2).

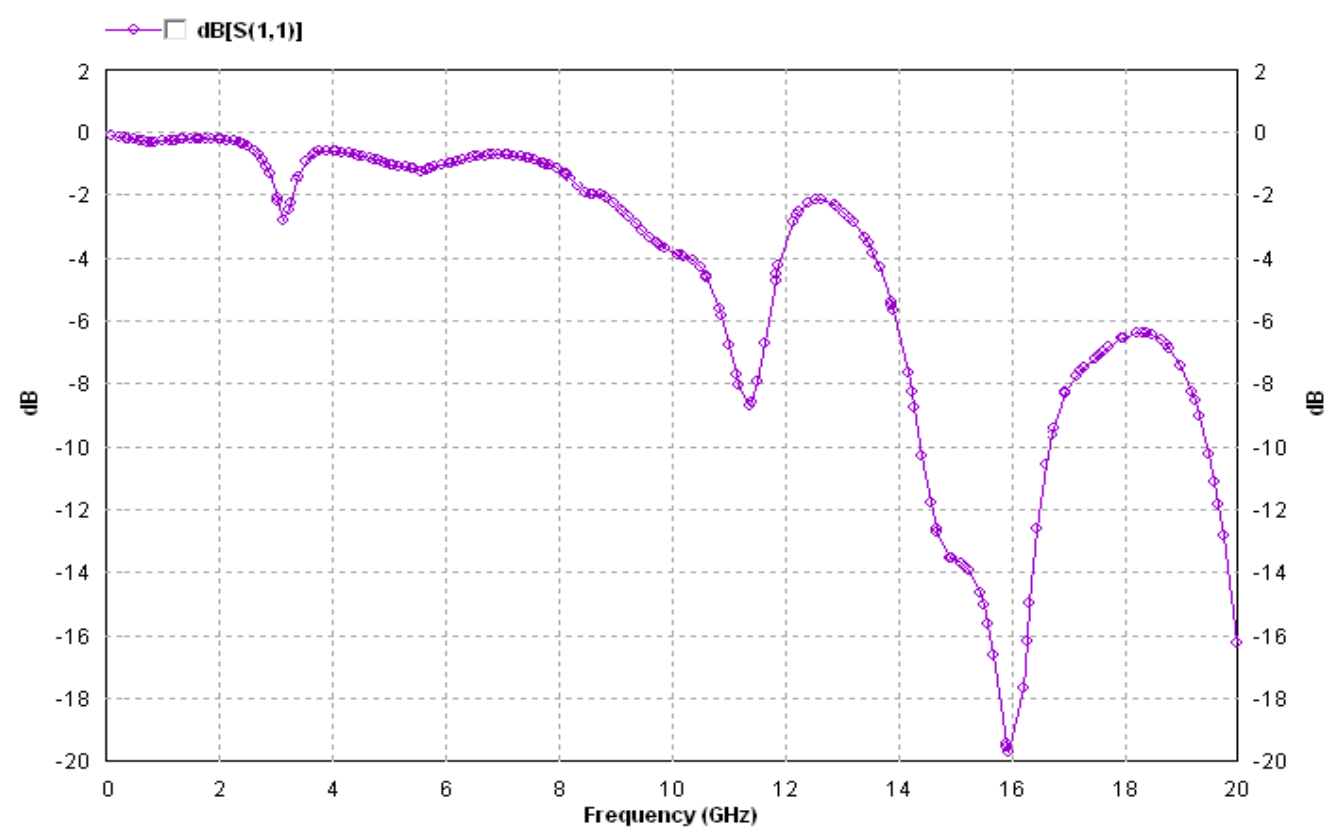

Fig.2. Simulated return loss (IE3D) 


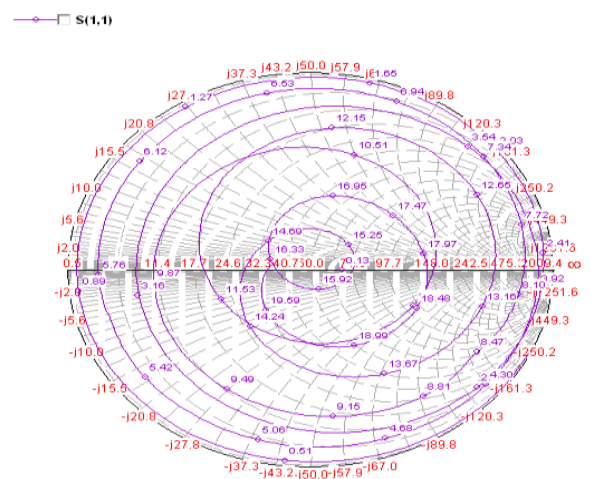

Fig.3. Smith Chart.

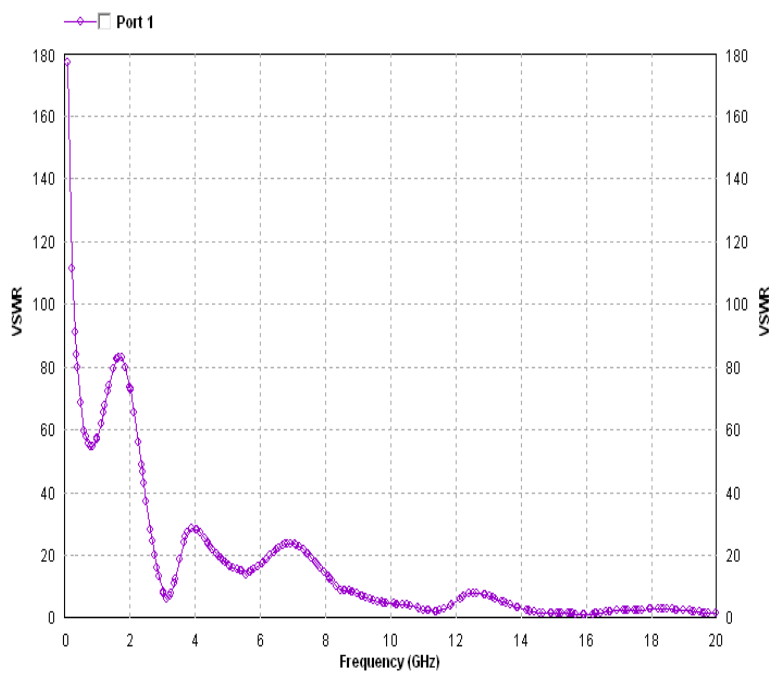

Fig.4. radiation pattern

\section{Conclusion}

A novel compact double-T monopole antenna for dual wideband wireless communications systems has been designed. The simulation result obtained by IE-3D shows good agreement with the measured results. It is shown that the proposed antenna covers two wideband from 2.3 to $3.4 \mathrm{GHz}$ and 4.95 to $5.85 \mathrm{GHz}$. The simulated radiation patterns at 2.7 and $5.4 \mathrm{GHz}$ were presented. Similarly to the conventional monopole antenna, the radiation patterns of the proposed dual wideband antenna are nearly omni-directional over the operating bandwidth (H-plane).

\section{References}

[1] M. John and M. J. Ammann, "Ultra-wideband wireless system integrated antenna for multiband multi-national wireless combined with GSM1800/PCS1900/IMT2000 + extension,” Microwave and Optical Technology Letters. Vol. 48, No. 3, March 2006

[2] Yen-Liang Kuo and Kin-Lu Wong, "Printed Double-T Monopole Antenna for 2.4/5.2 GHz Dual-Band WLAN Operations" IEEE Transactions on Antennas and Propagation, Vol. 51, No. 9, September 2003

[3] Y. H. Suh and K. Chang, "Low Cost Microstrip-fed dual frequency printed dipole antenna for wireless communications" Electron. Lett, Vol. 36, Jully 2000

[4] Tae-Hyun Kim and Dong-Chul Park, "Compact Dual-Band Antenna with Double L-Slits for WLAN Operation", IEEE Antennas and Wireless Propagation Letters, Vol. 4, 2005.

[5] D. Nashaat, H.A.Elsadek and H Ghali, "Dual- band reduced size PIFA antenna with U-slot for Bluetooth and WLAN applications", IEEE Proc. on Antennas and Propagation Society Int. Symp, vol 2, pp 962-965, 2003.

[6] C.C.Lin, G.Y.Lee and K.Y.Wong, "Surface mount dual-loop antenna for 2.4/5 GHz WLAN operations", Electron. Lett. , vol 39, pp. 1302-1304, Sept. 2003

[7] Y.L.Kuo and K.L.Wong, "Printed double-T monopole antenna for 2.4/5.2 GHz dual band WLAN operations", IEEE Transaction Antennas and Propagation, vol. 51, no 9, pp 2187-2192, Sept. 2003.

[8] Y.H.Suh and K.Chang, "Low cost microstriped dual frequency printed dipole antenna for wireless communications", Electron. Lett. vol. 36, pp. 1177-1179, Jul 62000. 